\title{
The Body and the Brain in Classrooms: On Matter and Social Context
}

\author{
Edyta Just \\ Linköping University, Linköping, Sweden \\ Email: edyta.just@liu.se
}

How to cite this paper: Just, E. (2020). The Body and the Brain in Classrooms: On Matter and Social Context. Creative Education, 11, 693-709.

https://doi.org/10.4236/ce.2020.115051

Received: March 29, 2020

Accepted: May 9, 2020

Published: May 12, 2020

Copyright $\odot 2020$ by author(s) and Scientific Research Publishing Inc. This work is licensed under the Creative Commons Attribution International License (CC BY 4.0).

http://creativecommons.org/licenses/by/4.0/

\begin{abstract}
In this paper, the body as subject is seen as the focus of learning generic skills and competences such as criticism and creativity where learning is conceptualized as a complex making of meaning. I want to deepen an understanding of meaning making processes and of what occurs in learning skills and competences such as criticism and creativity. I will attempt to do it by focusing on the embodiment and embeddedness of a learner. I will work with a psychological constructionist account of the brain basis of emotion - the conceptual act model (Lindquist et al., 2012; Barrett et al., 2014), my own theoretical reflections, which are built on the conceptual act model and the Deleuzian and Guattarian $(1987,2009)$ philosophical accounts of affect, concept and stratum, and the theories developed within the field of Gender Studies that focus on body/matter and intersectionality. By discussing various theories in an experimental manner (i.e., I read theories that belong to different fields of knowledge such as Neuroscience, Philosophy, Gender Studies together to find out what results this may have), I will try to reflect on meaning making processes and on what occurs in learning skills and competences such as criticism and creativity but also on the implications this may have for pedagogy.
\end{abstract}

\section{Keywords}

Generic Competences, Criticism, Creativity, Learning, Meaning Making, Body, Embodiment, Embeddedness

\section{A Rhizomatic Beginning}

In this paper, the body as subject is seen as the focus of learning generic skills and competences such as criticism and creativity where learning is conceptualized as a complex making of meaning. But what do we know about meaning making processes and what occurs in learning skills and competences such as criticism and creativity? 
In the chapter "Affect and Concept or Zero $\infty$ Gravity Consciousness" (Just, 2017) I conceptualize generic skills and competences as an ability of the subject "to become an immanent expression of difference; [to] perceive and think differently; reject representational manners of comprehension; go beyond the beaten track; resist timeworn customs, habits, beliefs, and opinions; escape easy interpretations and well-too-familiar doxa, and affirmatively welcome the novelty of being and acting (...)" (Just, 2017: p. 11). In the chapter I also claim, following Deleuze \& Guattari $(1987,2009)$ that to achieve and to have generic skills and competences means to be able to become an affect (i.e., to experience a lack of meaning) and a concept (i.e., to generate a new meaning), and that one facilitates the other (i.e., confusion, wonder, surprise (affect) may enable creation of a novel meaning (concept)). In addition, I underline that one needs to also become a stratum (i.e., a habitual meaning) to endure the engendered novelty.

In two following the chapter articles "Daring to Dare: Theoretical Experiment for Pedagogical Practices and Body-Brain-Embedded Subject" (Just, 2016) and "Daring the Meaning, or Cyberspace that Matters. Criticism-Creativity and Online Education" (Just, 2018) I develop this thinking further by focusing on two generic skills, criticism and creativity, and by discussing and unpacking the process of making meaning and by referring to it, following Lindquist et al. (2012) and Barrett et al. (2014), as situated conceptualizations which entail thinking, feeling and doing, and by suggesting that situated conceptualizations can be approached as affect, concept and stratum (following Deleuze \& Guattari $(1987,2009)$ ). In this sense achieving and having generic skills and competences such as criticism and creativity is linked to a complex making of meaning where meaning making of the experienced external and internal sensations (that entails thinking, feeling and doing) is approached as an ability to experience a lack of meaning (affect), new meaning (concept) supported by an experienced habitual meaning (stratum) that helps to endure and sustain the created novelty. Or put differently "criticism and creativity can be approached as an ability to challenge and problematize meaning of the experienced external and internal sensations including experience of emotions, to become surprised, to generate and conjure new meaning, which is new forms of thinking, feeling and acting, and to continually dare it" (Just, 2018: p. 2017). Simultaneously, I show how those theories (by Lindquist et al. (2012); Barrett et al. (2014); Deleuze \& Guattari $(1987,2009))$ separately and when experimentally combined together can motivate pedagogical practices that aim to support students in developing critical-creative abilities.

In this paper, I want to deepen an understanding of meaning making processes and of what occurs in learning skills and competences such as criticism and creativity. I will attempt to do it by focusing on the embodiment and embeddedness of a learner. I will work with a psychological constructionist account of the brain basis of emotion - the conceptual act model (Lindquist et al., 2012; Barrett et al., 2014), my own theoretical reflections, which are built on the conceptual act model and the Deleuze \& Guattari $(1987,2009)$ philosophical accounts of affect, concept and stratum, and the theories developed within the field of Gender Stu- 
dies that focus on body/matter and intersectionality. By discussing various theories in an experimental manner (i.e., I read theories that belong to different fields of knowledge such as Neuroscience, Philosophy, Gender Studies together to find out what results this may have), I will try to reflect on meaning making processes and on what occurs in learning skills and competences such as criticism and creativity but also on the implications this may have for pedagogy.

\section{On Meaning Making Process and Situated Conceptualizations}

Let me start by briefly outlining the theory which I work with and which concerns a meaning making process. A psychological constructionist account of the brain basis of emotions-the conceptual act model (Lindquist et al., 2012; Barrett et al., 2014) focuses on processes of meaning making of external and internal sensations including experience of emotions. It is a theory that discusses how the brain processes external (exteroceptive sensory information/information from the world) and internal, bodily sensations (interoceptive sensory information/information from the body/core affect) to make meaning. According to this theory, to understand what the external and internal input is, the brain creates novel situated conceptualizations by linking current external and internal sensations with accumulated conceptual knowledge (Barrett et al., 2014: p. 451). This is possible due to the fact that "knowledge is stored and represented in the same format (...) as the sensations" (Barrett et al., 2014: p. 451). Crucially, every concept "emerges from different multimodal systems in the brain (...) [and] particular modal areas of the brain store information about the category" (Barrett et al., 2014: p. 452). Conceptual knowledge for a given category develops for properties, relations, rules, other objects, setting, actions, words, events or internal states related to that category (Barrett et al., 2014: p. 452). Thus, when the brain creates a novel conceptualization, it "produces a conceptual state using multimodal information about entire situations" (Barrett et al., 2014: p. 452). Therefore, to encapsulate, "to conceptualize/make meaning is (...) to link external and internal sensations with existing knowledge; to determine what and why a given input is and to create novel conceptualization that may ['contain'] the past and present [external/internal] sensations, actions, etc.” (Just, 2016: p. 295). This allows to conclude that when meaning (a novel situated conceptualization) is created it entails an interconnection between thinking, feeling and doing what indicates that to make meaning means to think, to feel and to act. Moreover, it also enables to state that the existing and accumulated conceptual knowledge (what can also be referred to as the past experience) plays an important role in the meaning making process. The brain retrieves, so to say, its prior experience to make sense of here and now. As such it is possible that "what [one has] experienced in the past is very likely what [one] will experience in the present, because stored representations of the past help to constitute the present" (Barrett et al., 2014: p. 450). The prior experience, the conceptual knowledge, the former thinking-feeling-doing can influence the here and now by adding new features to and modifying sensorial input 
(Barrett et al., 2014: p. 448). Yet, the here and now can make an impact on and change the existing conceptual knowledge. Importantly, during the process of meaning making, another process referred to as executive attention takes place. Executive attention is "the process by which some representations are selectively enhanced and others are suppressed" and it "foregrounds certain core affective feelings and exteroceptive sensory sensations in a moment, and guides which situated conceptualizations are brought to bear to make meaning of those sensations in the given context" (Lindquist et al., 2012: p. 125). Executive attention "can be exerted both volitionally and without the conscious experience of volition" (Lindquist et al., 2012: p. 125). Interestingly, the theory claims that mental causation is probabilistic (Barrett et al., 2014: p. 455). This means that it cannot be easily anticipated how meaning making process will advance.

With regard to emotions, according to a psychological constructionist account of the brain basis of emotions - the conceptual act model, they stand for situated conceptualizations and they "emerge when people make meaning out of sensory input from the body and from the world, using knowledge of prior experiences" (Lindquist et al., 2012: p. 123). When the brain makes meaning/creates situated conceptualizations, it may (or may not) conceptualize an internal sensation as an emotion and as a particular emotion: interoceptive sensory information can be conceptualized as "a physical symptom (...) a simple feeling (...) or an instance of a discrete emotion category (e.g., anger vs. fear)" (Lindquist et al., 2012: p. 124). Thus, "[t]he experience of emotions similarly to other situated conceptualizations does depend on conceptual knowledge, executive attention and internal and external sensations" (Just, 2016: p. 296). It depends on the process of making meaning i.e., linking internal and external input with the accumulated knowledge whether a given internal sensation is conceptualized as an emotion or not.

\section{On Situated Conceptualizations, Affect, Concept, and Stratum}

In my two previously mentioned articles, I claim that generic skills such as criticism and creativity are linked to a process of meaning making where making of meaning of external and internal sensations is approached as, to repeat briefly, an ability to experience a lack of meaning (affect), a new meaning (concept) supported by an experienced habitual meaning (stratum) that helps to endure and sustain the created novelty. What does this entail and imply? Given that Deleuzian/Guattarian affect "indicates lack of meaning, conceptualization can be seen as potentially turning into a particular surprise or state of the brain's (...) wonder" (Just, 2018: p. 2020). Given that Deleuzian/Guattarian concept points to a creation of a new meaning, situated conceptualization approached as concept signalizes an ability of the brain to generate a new meaning of internal and external sensations and "to create a new combination of external and internal sensations (and actions), and as such create a new conceptual knowledge for a given category that incorporates properties, relations, rules, objects, settings, actions, words, events or internal states related to that category thus, able to think, feel 
and act differently" (Just, 2018: p. 2020). Since, following Deleuze \& Guattari (2009), affect can facilitate concept, "it can be speculated that once a given input leads to a confusion of the brain (...) such confusion can facilitate a creation of a novel meaning for a given external and/or internal input” (Just, 2018: p. 2020). Furthermore, since Deleuze \& Guattari (2009) claim that affect should be intertwined with concept as this allows meaning to always be "on the move," to think about conceptualization as an entanglement of affect and concept is to think about it "as a state where new meaning is continually engendered and as a state where final meaning is postponed and/or perhaps never reached" (Just, 2018: p. 2020). Finally, given that stratum should accompany affect and concept, to approach conceptualization as an intertwinement of affect, concept and stratum, "where lack of meaning, new meaning and habitual meaning complement each other, may show that for the [brain] to remain open to indetermination, novelty and change it has sometimes to think in the customarily ways (...) in order to endure and sustain an occurring and experienced lack of meaning and novel sense" (Just, 2018: p. 2021).

\section{The Body and the Brain: On Matter}

In this paper, the body as subject is seen as the focus of learning. To deepen an understanding of meaning making and of what occurs in learning skills and competences such as criticism and creativity, I concentrate on the embodiment and embeddedness of a learner. In this part of the paper, I approach the embodiment and embeddedness of a learner via the prism of the matter. I start with discussing a conceptual alignment of embodiment, embeddedness, matter, and mental activity. Then I read the conceptual act model, my own theoretical reflections, built on the conceptual act model and the Deleuzian and Guattarian philosophical accounts of affect, concept and stratum, together with the reflections on, to repeat briefly, the embodiment, embeddedness, matter, and mental activity.

The identity position or monism claims that "mind is brain activity" and that one "cannot have mental activity without brain activity" (Kalat, 2009: p. 6). The brain, the body, cells including neurons and glia, genes, neurotransmitters and hormones, etc., are the foundation for mental activity. The brain, the body, the bodily matter form the basis of cognition, perception, action, thinking, emotion, and memory, they are the basis of conscious and unconscious, volitional and automatic mental processes. Braidotti writes, "[w]ith reference to molecular biology, genetics, and neurology — to mention just a few-the body today can and should be described adequately and with serious credibility (...) as a sensor, an integrated site of information networks. It is also a messenger carrying thousands of communication systems: cardiovascular, respiratory, visual, acoustic, tactile, olfactory, hormonal, psychic, emotional, erotic. Co-ordinated by an inimitable circuit of information transmission, the body is a living recording system, capable of storing and then retrieving the necessary information and processing it at such speed that it can react 'instinctively' (...) The body is not only multifunctional but also in some ways multilingual: it speaks through temperature, motion, speed, 
emotions, excitement that affect cardiac rhythm and alike" (Braidotti, 2002b: p. 230). The matter matters. The parts of an eye, optic nerve, optic chiasm, thalamus, the primary and the secondary visual cortex, temporal cortex and parietal cortex participate in processing the visual information. The parts of an ear, auditory nerve, brainstem, midbrain, thalamus, and the primary auditory cortex participate in sound processing. The hippocampus may be important for a recent memory and the prefrontal cortex for working memory and reasoning. The skin's somatosensory receptors respond to touch and temperature. Importantly, the body is in an internal motion, there are countless-matter-connections and changes occurring (within the brain, within the body, between the body and the brain) the outcomes of which cannot be easily predictable. An eye condition may influence perception, a thyroid condition may have an impact on mood, lowering dopamine level (e.g., Parkinson's disease) affect, among others, motor skills, mood, cognition, brain tumors may cause hallucinations, and so on and so forth-the list seems to be endless. The bodily changes can be represented in the brain and interpreted with the "help" of memory (e.g., the stomach hurts). They can also influence (e.g., alter, add to) the memory (e.g., so this is how it is to have floaters in your eyes). Furthermore, the body, the brain, the bodily matter is always embedded. It is an "eco-logical entity" (Braidotti, 2008: p. 182). As Braidotti points out the body is "(...) a script written by the unfolding of genetic encoding, a text composed by the enfolding of external prompts" (Braidotti, 2008: p. 180). This means that the body endlessly undergoes various encounters with its surroundings. The 'external' matter, to list just few examples: particles, sun, air, bacteria, viruses, other particulate matter such as e.g., $\mathrm{PM}_{2.5}$ or $\mathrm{PM}_{10}$ commonly referred to as pollution, texture/surface, things, objects, human and non-human forms, and so on and so forth, matters for the body and the brain and by extension it also matters for mental activity. As Deleuze and Guattari say, "(...) we become with the world (...) We become universes" (Deleuze \& Guattari, 2009: p. 169). Let us think for a moment about sun or rain drops, shapes during the night and during the day, over illuminated by lamps areas, dripping taps, scents, stench, soft chair, over-heated apartments (when the heater broke down and you just cannot turn it off), sweet chocolate, caffeine, pollen, antihistamines, $\mathrm{PM}_{2.5}$, Escherichia coli, and how they may impact our mental activity. The matter matters. At the same time, the outcomes of the interactions between the body, the brain and the external matter cannot be effortlessly anticipated. A given chemical substance may or may not cause a lung cancer that then may or may not spread to the brain and cause cognitive impairments. The thirty degrees sunny day may go unnoticed on Monday but knock one down on Wednesday. An over illuminated by lamps area may or may not be consciously registered and still ends up in anxiety and one leaving quickly such area. A given scent may or may not be consciously registered and cause positive mood or it may retrieve a memory that will or will not influence the present. The memory can come to an aid by making sense of here and now, and the here and now may influence the memory. The body, the brain, the bodily matter with all its internal interactions as well as external matter, 
which has an impact on/interacts with the body, the brain, the bodily matter, matter with regard to mental activity.

\section{Reading Together}

To think about meaning making process when internal and external sensations are being linked with conceptual knowledge and to think about becoming an affect, concept and stratum is to think also about the body matter-sine qua non of this process. The body matter (and here I also mean the brain) to put it simply, makes it possible to store conceptual knowledge, to experience internal and external sensations and to create meaning of those sensations. The body matter also conditions whether and how the internal and external sensations are experienced and made meaning of even though "no matter how hard you try, you cannot gain introspective access to the processes in your brain that underline using stored knowledge to make incoming sensations meaningful" (Barrett et al., 2014: p. 449). The meaning making processes happen constantly, "during every moment of waking life, the brain takes in sensory input captured from the world outside the skin (light, vibrations, odors, etc.) and sensations captured from within the body that holds the brain (the internal "milieu"), and uses knowledge from prior experience (also variously called concepts, memories, associations, beliefs, predictions, etc.) - stored in association cortex and in sensory neurons and subcortical regions-and make those sensory inputs meaningful" (Barrett et al., 2014: p. 448). Since, an inflow of e. g., internal sensations and following it meaning making process may occur at any time (the power of matter) it might be that all attention centers around this very process (let us think for a moment about a headache or a toothache or a back pain or a full bladder). Furthermore, once the body, the brain matter takes in sensory input and produces meaning, other processes might also take place that may affect mental activity, e.g., the thyroid condition, the Parkinson's disease, chemical imbalance in the brain, etc. The body-brain does not exist in the vacuum but remains in ceaseless interactions with its surroundings. Therefore, to think about meaning making process when internal and external sensations are being linked with conceptual knowledge and to think about becoming an affect, concept and stratum is to think also about those interactions. Once the body, the brain matter takes in sensory input and produces meaning (e.g., when attending a lecture), other interactions with external matter may occur that may have an impact on mental activity, e.g., the number of coffee cups drunken, the antihistamines taken in the morning, the cold one has, the overheated or over illuminated room one seats in. At the same time, the external matter (think about blossoming trees or a lawnmower working just outside one's window or a really un/comfortable chair) may completely grabs one's attention. It could also be that a given scent or object may retrieve a memory and again one will only be able to focus on that memory and for a moment "get lost" in the present past. The body, the brain and the external matter are tightly interconnected. For example, an eye condition may influence what and how is seen or an ear condition may influence what and how is heard; a damage to area MT (middle-temporal cortex) can cause motion blindness (one sees an 
object, but cannot see whether the object is moving or not or the movement is seen but one cannot say which direction and how fast the object is moving (Kalat, 2009: p. 177)); a damage in parts of the superior temporal cortex can cause motion deaf (one hears sounds, but cannot detect that a source of a sound is moving (Kalat, 2009: p. 194)); the sun or a lamp (external matter) may have an impact on whether/how/what one's sees. The connections between the body, the brain and external matter condition how the sensations are represented and stored. They also condition how the incoming sensations from the world and from the body can be interpreted (made meaning of). Importantly, stating that the body, the brain and the external matter play a role in making of meaning and in becoming affect, concept and stratum is not to say that there is no volition. To repeat briefly, according to the conceptual act model when the meaning making takes place executive attention, which "can be exerted both volitionally and without the conscious experience of volition," "foregrounds certain core affective feelings and exteroceptive sensory sensations in a moment, and guides which situated conceptualizations are brought to bear to make meaning of those sensations in the given context" (Lindquist et al., 2012: p. 125). Though, making of meaning can happen automatically, it can also occur volitionally and in both instances one can become an intertwinement of affect, concept and stratum, one can challenge and problematize meaning of the experienced external and internal sensations including experience of emotions, become surprised, generate new meaning and constantly dare it, one can become critical and creative.

\section{The Body and the Brain: On Social Context}

In the previous part of the text, to deepen an understanding of meaning making and of what occurs in learning skills and competences such as criticism and creativity I have approached the embodiment and embeddedness of a learner via the prism of the matter and focused on the conceptual alignment of embodiment, embeddedness, matter and mental activity. In this part of the paper, I situate embodiment and embeddedness of a learner in a social context. I begin by discussing a conceptual alignment of embodiment, embeddedness, mental activity and social context. Then, following the structure set in the previous paragraph, I read the conceptual act model, my own theoretical reflections, built on the conceptual act model and the Deleuzian and Guattarian philosophical accounts of affect, concept and stratum, together with the reflections on the embodiment, embeddedness, mental activity and social context.

Certainly, I am not going to reflect on all the possible "interactions" between embodiment, embeddedness, mental activity and social context as this would require a never-ending review of the rich scholarship in Psychology, Psychiatry or Philosophy. I also do not intend to bring to the fore all that have been written on this topic by feminist researchers who for decades now make vital and indispensable interventions and contributions to an understanding of embodiment, embeddedness and social context and their mutual relations. What I plan to highlight here, however, is that one's embeddedness, the social context one lives 
in with all its societal and power relations built around and discourses and beliefs concerning various forms of embodiment, gender, sex, sexuality, ethnicity, age, dis/ability, class and religion do not remain indifferent to one's mental activity. Certainly, practices and discourses differ across space and time yet the body works as a signifier with a particular signified always already "attached" to it and to say it directly certain groups remain in an underprivileged position comparing to others. It is for those reasons that the concept of intersectionality (Crenshaw, 1991) has been applied by feminist scholars in order to “(..) refer to aspects of identity [gender, race/ethnicity, sexual orientation, age, [dis/ability], religion] and how they interact and affect equality" and how and why "marginalized groups experience not only multiple but also particular forms of inequalities" (Woodward, Bagilhole, \& Franken, 2009: p. 9; Squires, 2009: p. 53). The feminist researchers have published extensively on various forms of violence, exclusion and discrimination directed at certain forms of embodiment, gender, sex, sexuality, ethnicity, age, dis/ability, class and religion. Given the scope of this paper, it is not possible to address, discuss and do justice to all feminist interventions concerning various axes of differentiation and related to them practices and discourses. For the purpose of this paper, let me just mention that some forms of embodiment, certain genders, sexes, sexualities and ethnicities are still marked negatively, kept inferior or excluded and discriminated due to, among others, historical, political, economic, medical and cultural conditions, and patriarchal ways of thinking and its visible and invisible power mechanisms. Of course, this is not to say that change is impossible or that certain differences cannot be positively reconceptualized but to stress that there is still a long way to go for the harmful practices and discourses ceasing to exist. The practices and discourses steaming out of social context do affect the bodies in question. Braidotti writes, " $[\mathrm{t}]$ he embodiedness of the subject is a form of bodily materiality, not only of the natural, biological kind. The body is the complex interplay of highly constructed social and symbolic forces: it is not an essence, let alone a biological substance, but a play of forces within a complex web of social and symbolic relations. (...) Whatever semblance of unity there may be is embodied and performed as a choreography of many levels into one socially operational self" (Braidotti, 2002a: p. 160). The practices and discourses affect the body, the brain activity and mental activity, and have an impact on the ways one may think, feel and act in. Olga Cielemęcka makes such point when stating that " $[\mathrm{m}]$ arkers of difference such as class, race, gender, sexuality, age, dis/ability (...) all play a significant role in how bodies act, speak, move and breathe in (...) spaces" (Cielemęcka, 2017: p. 153). The social context one lives in "participates" in creation of memories and as such the body "remains a bio-social entity, that is to say a slab of codified, personalized memories" (Braidotti, 2002b: p. 21). According to Cognitive Psychology the import of memory is not to be underestimated. Though one tends to forget and the accuracy of one's memory might be questioned, without memory " $[w]$ e would not recognise anyone or anything as familiar. We would be unable to talk, read or write because we would remember nothing about language. We 
would have extremely limited personalities because we would have no recollection of the events of our own lives and therefore no sense of self' (Eysenck \& Keane, 2015: p. 207). If personal experiences and events of our own lives (stored in episodic memory) but also "knowledge about the world, concepts, language and so on" (stored in semantic memory) (Eysenck \& Keane, 2015: p. 264) had and/or still have to do with exclusion, violence, discrimination and precarity and certain harmful beliefs and convictions then I invite us all to for a moment to consider and reflect on how these may influence one's body, one's mental activity, one's ways of thinking, feeling and acting. By saying this I want in no way to claim that one is a passive and inactive marionette. One has "capacity for simultaneously incorporating and transcending the very variables-class, race, sex, nationality, culture, etc. - which structure it" and one "is a process, made of constant shifts and negotiations between different levels of power and desire" (Braidotti, 2002b: pp. 21-22). What I want to say, however, is that harmful and detrimental practices and discourses concerning various forms of embodiment, gender, sex, sexuality, ethnicity, age, dis/ability, class and religion matter for the body, for the brain and for mental activity.

\section{Reading Together}

To think about meaning making process when internal and external sensations are being linked with conceptual knowledge and to think about becoming an affect, concept and stratum is to think also about practices, discourses, societal and power relations built around forms of embodiment, gender, sex, sexuality, ethnicity, age, dis/ability, class and religion. All those practices, discourses and power relations result in personal experiences, events of one's life that form one's conceptual knowledge. Since conceptual knowledge is crucial in the process of making meaning of all incoming sensations then it can be said that practices, discourses and power relations that resulted in personal experiences may condition the created meaning of the incoming sensations and as such ways of thinking, feeling and acting. If you have been told that you are unable to write or speak interestingly, drive a car/plane or do good in math, if you have been showed that public sphere and complex thinking is not your thing, if you have been denied an access to study/work or made believe in your supposed inferiority, lacking, passivity or other negative personality adjectives then the way you make sense of the arriving sensations and of the world; the way you think, feel and act remains influenced by those experiences. The events and incoming sensations do not have to do directly with those practices and discourses yet since the latter formed conceptual knowledge, since the conceptual knowledge can add new features and modify sensorial input, and since the meaning making process is probabilistic they (i.e., practices and discourses) may influence the meaning that gets produced and manners of thinking, feeling and acting. Sometimes, your imposed convictions about e.g., your inability to speak in public (in e.g., spacious rooms) when you just listen to somebody who seemingly effortlessly "rocks" an audience and you are just about to be a next speaker will make you not hear what is being said but possibly leave the room or feel scared. This somehow resonates with 
what Olga Cielemęcka writes when she refers to an interesting quote from Cixous to show feelings of inadequacy and awkwardness some may feel when just about to speak: "[T] he torment of getting up to speak. Her heart racing, at times entirely lost for words, ground and language slipping away-that's how daring a feat, how great a transgression it is for a woman to speak-even just open her mouth-in public" (Cixous, 1976: p. 880 in Cielemęcka, 2017: p. 154). Furthermore, if what is happening here and now is partially or completely linked to practices and discourses that have to do with exclusion, discrimination, harmful beliefs and detrimental stereotypes then the similar, former experiences and associations may entirely influence the meaning making process and in fact become even stronger and solidify. Certainly, in all instances (when incoming sensations are not directly linked to discriminatory practices and discourses and when they are partially or completely linked to them) the meaning making process cannot be completely predicted. This is again due to the fact that mental causation is probabilistic but also due to the executive attention that can be exercised volitionally e.g., one can volitionally influence the meaning making process: Why do I even bother? I will not be influenced by this speaker, by this room. I will not give in to fear. Is that fear really? I will not leave the room, I will stand up and speak. And perhaps next time I will bring my best friend with me. One is a "process" never a static and passive marionette. One can always experience, automatically or volitionally, a lack of meaning and a new meaning. One can become critical and creative. And the existing conceptual knowledge can change and get transformed. Furthermore, everything that is happening in the present, all the incoming external and internal sensations can result, again automatically and volitionally, in new ways of thinking, feeling and acting. A particular positive practice, a positive event in a room you have always feared, a travel, a poem, a book or a movie can turn one into affect and concept in thinking, feeling and acting. Think about a daring and challenging art exhibition on writing-and then suddenly: Is that writing? Writing is such a powerful tool indeed, I may love it, I can write an appealing novel, I am writing and enjoying it actually. My words may mean something and have an impact. Perhaps my writing may support somebody in writing, too. Affect and concept paired together can continue as one may always try to search for affect-concept in order to never stop becoming one and if the lack of meaning and new meaning are sometimes a bit too much to take one can rest for a while on a striated sofa of the habitual and the familiar.

\section{Implications for Pedagogy}

There are numerous and important scholarly reflections and interventions on the body/the brain, external matter, mental activity and learning (among others e.g., Michael W. Eysenck, \& Mark T. Keane (2015), James Kalat (2009)); on the body, external matter and learning/pedagogy/education (among others e.g., Anna Hickey-Moody (2017, 2009); Malou Juelskjær (2017); Malou Juelskjær \& Dorthe Staunæs (2016); Sharon McDonough et al. (2016); Jos Boys (2010)) and on the 
various axes of differentiation, discrimination, exclusion and learning/pedagogy/education (among others e.g., Nina Lykke (2012); Kevin Kumashiro (2000); Bell Hooks (1994)). The message, which comes from such publications, is clear: the body, the external matter, the existing discourses and practices that concern various forms of embodiment cannot be taken off the learning/pedagogical/educational equation, and this message informs and inspires my own considerations regarding the issues discussed in this text.

As mentioned at the beginning, in this paper the body as subject is seen as the focus of learning generic skills and competences such as criticism and creativity with learning conceptualized as a complex making of meaning. In order to expand an understanding of meaning making and of what happens in learning skills and competences such as criticism and creativity, I have focused on and approached embodiment and embeddedness of a learner via the prism of the matter and social context and discussed various theories in an experimental manner (i.e., I have read theories belonging to different fields of knowledge together). In this part of the paper, I intend to reflect on the implications this may have for pedagogy.

Reading through the rich scholarship on embodiment, embeddedness and education, it seems that the body (and by body I also mean here an embodied brain), matter and existing discourses and practices that concern various forms of embodiment require attention and respect in classrooms. Students and teachers are embodied and embedded beings and so the body, the embodied brain (thus part of the body), matter, discourses and practices should never fall outside thinking about pedagogy.

The bodies and the experiences linked to discourses and practices differ and as such the processing of information may differ, too. To put it very simply, eyes, ears, intersectional experiences are not all the same. Bodily matter connections and changes occurring within the brain, within the body and between the body and the brain are not alike for everybody. Importantly, the outcomes of the connections and changes may not be consciously noticed but still affect mental activity. Certainly, they can be consciously registered and reflected upon the moment they are happening. The same can be said about the encounters with the external matter. The past, recent or present interactions between the body and the external matter and the outcomes of such interactions may not be the same for everybody and they can also affect mental activity does not matter whether consciously or unconsciously processed. Life histories and experiences connected to discourses, practices and power relations that concern various forms of embodiment and how they (i.e., experiences) may condition living/being in the present are equally not alike for everybody. The meaning making and becoming affect/concept/stratum in relation to any pedagogical endeavor can be conditioned by the state of the body with all its internal and external (matter) interactions as well as by the experiences linked to harmful and discriminatory discourses and practices. Furthermore, the bodies constantly produce meaning that is they feel, think and act, and it can happen automatically or volitionally, con- 
sciously or unconsciously. The becoming of affect, concept and stratum follows a similar logic. Thus, the meaning making and becoming affect/concept/stratum can be as much directed towards pedagogical undertakings (i.e., content, teaching methods, learning activities) as it can be towards the body and its internal and external (matter) interactions or anything that may possibly resonate with aforementioned difficult experiences. Even if the classroom is seemingly silent (prepared to give/acquire the knowledge/skills) the bodies, the brains, the matter, the experiences pulsate, speak in their own language, work, move, tremble, shout, scream, and go on. Those beautifully 'pulsating' bodies/brains/(internal and external) matter/experiences linked to discourses and practices deserve recognition and, as said, attention and respect. Yet, what does this entail? How such statement (about recognition, attention and respect) can be taken into consideration in pedagogy? Perhaps, the first step would be to actually nomen omen recognize this, let me allow to use this word, pulsation? To become aware of it and in this awareness to really respect and pay attention to it. This recognition, awareness, respect and attention can possibly be understood in terms of unconditional hospitality in a Derrida's sense (2000). The unconditional hospitality i.e., a radical openness to the other with a minor, so to say, addition as in this context what I mean by the other is a beautifully pulsating body/brain/matter/experience. This could lead to a body/matter/intersectional experience-aware pedagogy ${ }^{1}$ that is pedagogy that acknowledges the seemingly invisible; that acknowledges that bodies (including the brain as a part of the body), the bodily matter (and its interactions) and external matter (and its interactions with the body) affect mental activity; that acknowledges that intersectional experiences affect mental activity and that those affections matter as much in the classrooms as all efforts undertaken to provide/achieve given knowledges/skills. Perhaps such recognition/awareness/respect/attention could fuel pedagogies that tailor themselves more to the students' and teachers' singularities? Pedagogies that focus on affirmation of such singularities instead of aiming for unifying them. There is a famous, popular and wellknown quotation by Albert Einstein that states, "Everybody is a genius. But if you judge a fish by its ability to climb a tree, it will live its whole life believing that it is stupid"-perhaps there is high-time to take that quote much more seriously into consideration when thinking about pedagogy. Thus, when one thinks about criticism and creativity as an ability to, automatically or volitionally, challenge and problematize meaning of the experienced external and internal sensations including experience of emotions, become surprised, generate new meaning and constantly dare it vis-à-vis certain knowledges/skills, one should not forget about the body and its internal and external (matter) interactions but also about inter${ }^{1}$ Emilia Åkesson's (2014) concept of intersectional corpomaterial pedagogy resonates interestingly with my concept. Though there is a difference in definitions as for Åkesson intersectional corpomaterial pedagogy addresses the meaning of intersectional power dynamics to teaching/learning and merges this with a corpomaterial strand including an understanding of the subject as multiple, where the body and the material contains an equal ontological status as the hu(M)an and where affective processes are central to what happens/could happen in education, we both agree on the idea of combining an intersectional and corpomaterial perspective in pedagogies. 
sectional experiences. Importantly, however, perhaps, we could strive to actually increase the awareness of the body and its internal and external (matter) interactions but also of the intersectional experiences in the classrooms. Furthermore, it would be interesting to think about a body/matter/intersectional experience-aware pedagogy that actually support students and teachers in becoming affect/concept/stratum not only vis-à-vis certain knowledges/skills but also vis-à-vis one's body in its internal and external (matter) interactions but also intersectional experiences. In the two latter instances the question that begs an answer is "how"? And I must admit that this "how" is pretty challenging to confront. Difficult yet not entirely impossible but to transform the seemingly impossible into the possible more scholarly cooperation and reflection are necessary. To end this discussion, I also want to mention that the process of meaning making is probabilistic and as such not easy to predict. Furthermore, we, students and teachers, may never really know to what extent the body and its internal and external (matter) interactions matter; to what extent intersectional (and any other) experiences matter; to what extent the content and the form of a pedagogical endeavor matter with regard to the making of meaning and becoming affect/concept/stratum towards the body, intersectional experiences and knowledges/skills. The unpredictability of meaning making and of what may lay behind it, I think, should be written into a body/matter/intersectional experience-aware pedagogy equation. Yet, not as a burden or an obstacle but rather as a reminder that "full control" is an illusion and as an affirmation of the beauty of the unexpected.

\section{A Rhizomatic Ending}

I approach learning generic skills and competences via the prism of meaning making practices and think about criticism and creativity in terms of affect, concept and stratum. To expand a comprehension of meaning making and of what occurs in learning generic skills and competences such as criticism and creativity, I have focused on a conceptual alignment of embodiment, embeddedness, matter, social context and mental activity, and discussed different theories in experimental manner. I have also reflected on the implications my aforementioned discussions may have for thinking about pedagogy. Writing this paper, with a special focus put on meaning making and criticism and creativity, I have endeavored to add to the rich scholarship that discusses the body, the brain, matter, social context, education and pedagogy. Yet, I am aware that those discussions will and should continue. Since the meaning is always in the making there is still a lot to reflect on and say with regard to bodies, brains, matter, social context, making meaning, criticism and creativity, and contemporary classrooms. My own fascination with meaning making process, concepts of criticism and creativity, bodies/brains and their silent and sometimes extremely loud modi operandi, and pedagogy does not allow me to stop daringly reflect on the matter. In this paper, my thinking about meaning, generic competences, bodies, brains, matter and social context has resulted in reflections concerning meaning making and learn- 
ing generic skills but also in a proposition of a body/matter/intersectional experience-aware pedagogy. However, I am aware that my thinking, my reflections and my proposition situate themselves, to use the Deleuzian/Guattarian language, on a plane of a concept-affect with countless lines of flight, which is prone to endless deterritorializations and reterritorializations that I welcome with awe and curiosity. One of the possible lines of flight I would like to attach myself to, is a reflection on the body/brain and non-matter or energy and its implications for mental activity, and possibly for meaning making, concepts of criticism and creativity and certainly for pedagogy. I am not sure where such considerations may lead me but I follow the guidance of Wislawa Szymborska and Albert Einstein here who respectively say that "Whatever inspiration is, it's born from a continuous "I don't know" and that "Imagination will take you everywhere." So what a non-matter or energy pedagogy could be about?

\section{Conflicts of Interest}

The author declares no conflicts of interest regarding the publication of this paper.

\section{References}

Åkesson, E. (2014). Affectivity in the Classroom: A Contribution to a Feminist Corpomaterial Intersectional Pedagogy. Master's Thesis, Sweden: Linköping University.

Barrett, L. F., Wilson-Mendenhall, C. D., \& Barsalou, L. W. (2014). A Psychological Construction Account of Emotion Regulation and Dysregulation: The Role of Situated Conceptualizations. In J. J. Gross (Ed.), The Handbook of Emotion Regulation (2nd ed., pp. 447-465). New York: Guilford.

Boys, J. (2010). Towards Creative Learning Spaces: Re-Thinking the Architecture of Post-Compulsory Education. New York: Routledge. https://doi.org/10.4324/9780203835890

Braidotti, R. (2002a). Identity, Subjectivity and Difference: A Critical Genealogy. In R. Braidotti, \& G. Griffin (Eds.), Thinking Differently. A Reader in European Women's Studies (pp. 158-180). London and New York: Zed Books.

Braidotti, R. (2002b). Metamorphoses: Towards a Materialist Theory of Becoming. Cambridge: Polity.

Braidotti, R. (2008). The Politics of Life as Bios/Zoe. In A. Smelik, \& N. Lykke (Eds.), Bits of Life. Feminism at the Intersections of Media, Bioscience, and Technology (pp. 177-192). Seattle and London: University of Washington Press.

Cielemęcka, O. (2017). Let the Thinking Breathe. Corporeal Thinking in Classroom Settings. In: E. Just, \& W. Grahn (Eds.), Adventurous Encounters. Theories of Affect and Concepts in Generic Skills Education (pp. 151-169). Newcastle upon Tyne: Cambridge Scholars Publishing.

Cixous, H. (1976). The Laugh of the Medusa. Signs, 1, 875-893. https://doi.org/10.1086/493306

Crenshaw, K. (1991). Mapping the Margins: Intersectionality, Identity Politics, and Violence against the Women of Color. Stanford Law Review, 43, 1241-1299.

https://doi.org/10.2307/1229039 
Deleuze, G., \& Guattari, F. (1987). A Thousand Plateaus. Capitalism and Schizophrenia. London and New York: Continuum.

Deleuze, G., \& Guattari, F. (2009). What Is Philosophy? London and New York: Verso.

Derrida, J. (2000). Hostipitality. Angelaki, 5, 3-18. https://doi.org/10.1080/09697250020034706

Eysenck, M. W., \& Mark, T. K. (2015). Cognitive Psychology: A Student's Handbook (7th ed.). London and New York: Psychology Press, Taylor \& Francis Group. https://doi.org/10.4324/9781315778006

Hickey-Moody, A. (2009). Little War Machines: Posthuman Pedagogy and Its Media. Journal of Literary \& Cultural Disability Studies, 3, 273-280. https://doi.org/10.1353/jlc.0.0024

Hickey-Moody, A. (2017). Integrated Dance as a Public Pedagogy of the Body. Social Alternatives, 36, 5-13.

Hooks, B. (1994). Teaching to Transgress. Education as the Practice of Freedom. London: Routledge.

Juelskjær, M. (2017). Atmospheric Encounters: Generic Competences in Light of Posthumanist Teaching Practices with/on Affectivity. In E. Just, \& W. Grahn (Eds.), Adventurous Encounters. Theories of Affect and Concepts in Generic Skills Education (pp. 65-89). Newcastle upon Tyne: Cambridge Scholars Publishing.

Juelskjær, M., \& Staunæs, D. (2016). Designing Leadership Chairs: Experiments with Affirmative Critique of Leadership and Environmentality. Reconceptualizing Educational Research Methodology, 7, 35-51. https://doi.org/10.7577/rerm.1840

Just, E. (2016). Daring to Dare-Theoretical Experiment for Pedagogical Practices and Body Brain-Embedded Subject. Creative Education, 7, 293-301. https://doi.org/10.4236/ce.2016.72028

Just, E. (2017). Affect and Concept or ZeroøGravity Consciousness. In: E. Just, \& W. Grahn (Eds.), Adventurous Encounters. Theories of Affect and Concepts in Generic Skills Education (pp. 9-27.). Newcastle upon Tyne: Cambridge Scholars Publishing.

Just, E. (2018). Daring the Meaning, or Cyberspace that Matters. Criticism-Creativity and Online Education. Creative Education, 9, 2016-2036.

https://doi.org/10.4236/ce.2018.913147

Kalat, J. W. (2009). Biological Psychology (10th ed.). Boston, MA: Wadsworth Cengage Learning.

Kumashiro, K. (2000). Toward a Theory of Anti-Oppressive Education. Review of Educational Research, 70, 25-53. https://doi.org/10.3102/00346543070001025

Lindquist, K. A., Wager, T. D., Kober, H., Bliss-Moreau, E., \& Barrett, L. F. (2012). The Brain Basis of Emotion: A Meta-Analytic Review. Behavioral and Brain Sciences, 35, 121-202. https://doi.org/10.1017/S0140525X11000446

Lykke, N. (2012). Intersectional Gender Pedagogy. In A. Lundberg, \& A. Werner (Eds.), Gender Studies Education and Pedagogy (pp. 14-17). Gothenburg: Swedish Secretariat for Gender Research.

McDonough, S., Forgasz, R., Berry, A., \& Taylor, M. (2016). All Brain and Still No Body: Moving towards a Pedagogy of Embodiment in Teacher Education. In D. Garbett, \& A. Ovens (Eds.), Enacting Self-Study as a Methodology for Professional Inquiry (pp. 433-440). Herstmonceux, UK: S-STEP.

Squires, J. (2009). Multiple Inequalities, Intersectionality and Gender Mainstreaming: Potential and Pitfalls. In M. Franken, A Woodward, A. Cabo, \& B. Bagilhole (Eds.), 
Teaching Intersectionality: Putting Gender at the Centre (pp. 53-63). ATHENA3 Advanced Thematic Network in Women's Studies in Europe, University of Utrecht and Centre for Gender Studies, Stockholm University.

Woodward, A., Bagilhole, B., \& Martha, F. (2009). Teaching Intersectionality: Putting Gender at the Centre-Introduction. In M. Franken, A Woodward, A. Cabo, \& B. Bagilhole (Eds.), Teaching Intersectionality: Putting Gender at the Centre (pp. 9-13). ATHENA3 Advanced Thematic Network in Women's Studies in Europe, University of Utrecht and Centre for Gender Studies, Stockholm University. 